\title{
RESPOSTA HUMORAL DE BOVINOS VACINADOS CONTRA AS TOXINAS BOTULÍNICAS TIPOS C E DEM DIFERENTES FAIXAS ETÁRIAS
}

\section{V.C.M. Curci ${ }^{1}$, M.C. Zocoller-Seno ${ }^{2}$, A.H.C. Nogueira ${ }^{3}$, R.F. de Araujo ${ }^{4 *}$, T.C. Cardoso ${ }^{5}$, I.S. Dutra ${ }^{5}$}

${ }^{1}$ Polo Regional Extremo Oeste, Unidade de Pesquisa e Desenvolvimento de Araçatuba, Av. Alcides Fagundes Chagas, 122, CEP 16055-565, Araçatuba, SP, Brasil. E-mail: vlmcurci@apta.sp.gov.br

\section{RESUMO}

Foi verificada pelo teste de ELISA indireto a resposta humoral contra os toxoides botulínicos $\mathrm{C}$ e $\mathrm{D}$ em bovinos de diferentes idades. $\mathrm{O}$ estudo envolveu 90 animais, que foram divididos em três grupos $(\mathrm{n}=30)$, de acordo com a sua faixa etária; inferior a 2 anos de idade $(\mathrm{G} 1)$, entre 2 e 5 anos (G2) e superior a 5 anos (G3). Os grupos experimentais foram vacinados com duas doses de vacina antibotulínica bivalente (C e D) comercial, nos dias 0 e 42 após a primo-vacinação (booster). $\mathrm{Na}$ avaliação, quando realizada 30 dias após o booster, os animais do G3 apresentaram maior produção de anticorpos ( $<<0,05)$ em relação aos demais grupos. Entre o G1 e G2 não houve diferença significativa na resposta humoral contra a toxina $C$, no entanto, contra a toxina $D$, os animais do G1 apresentaram maior produção de anticorpos. Todos os grupos produziram uma resposta significativa de anticorpos contra as toxinas botulínicas após a $2^{\mathrm{a}}$ dose da vacina bivalente comercial, principalmente contra o tipo D.

PALAVRAS-CHAVE: Anticorpos, botulismo, Clostridium botulinum C e D, vacinação.

\section{ABSTRACT}

HUMORAL RESPONSE OF VACCINATED CATTLE AGAINST TOXINS OF CLOSTRIDIUM BOTULINUMTYPESC ANDD AT DIFFERENT AGES. Cattle humoral response against type Cand $\mathrm{D}$ botulinum toxoids (indirect ELISA) was verified in animals of different ages. The animals $(\mathrm{n}=$ 90) were divided in three groups ( $=30$ ): group one (G1): less than two years old; group two (G2): from 2 to 5 years old; group three (G3): more than 5 years old. The groups were vaccinated with two doses [ 0 and 42 days after primary vaccination (booster)] of bivalent (C and D) antibotulinum vaccine. Group three had higher antibody production $(\mathrm{p} \leq 0.05)$ compared to the other groups, 30 days after the booster. There was no difference (G1 and $G 2 ; p \geq 0.05)$ in the humoral response against $C$ toxin, however, against $\mathrm{D}$ toxin, group one had higher antibody production. It was possible to conclude that after two doses of the commercial bivalent vaccine all groups produced a significant antibody response against botulinum toxins, especially against D type.

KEY WORDS: Antibodies, botulism, Clostridium botulinum C and D, vaccination.

Obotulismo em bovinosé uma doença de grande importância econômica e sanitária como causa de mortalidade de bovinos adultos no Brasil (Dutra, 2001). Nesta espécie, a enfermidade está relacionada à contaminação ambiental pelos esporos do Clostridium botulinum tipos C e D e também ao manejo inadequado. A intoxicação dos animais ocorre pela ingestão da toxina pré-formada pelos esporos da bactéria. No Brasil, os surtos estão associados à deficiência de fósforo e à osteofagia, principalmente em animais criados extensivamente (TOKARNIA et al., 1970; DUTRA; DÖBEREINER, 1995; RIBAs et al., 1994), também a alimentos contaminados e armazenados inadequadamente (DUTRA, 2001) ou ainda pela veiculação hídrica (Dutra et al., 2001; SouzA et al., 2006). O conhecimento das causas da enfermidade é de grande importância para indicar a necessidade de vacinação entre outras medidas de controle.

Embora a osteofagia seja a maior responsável por surtos deintoxicação em fêmeas na fase reprodutiva,

${ }^{2}$ Universidade Estadual Paulista, Faculdade de Engenharia, Departamento de Biologia eZootecnia, Ilha Solteira, SP, Brasil. ${ }^{3}$ Instituto Biológico, Centro de Pesquisa e Desenvolvimento de Sanidade Animal, São Paulo, SP, Brasil. ${ }^{4}$ Universidade Estadual Paulista, Faculdade de Ciências Agrárias e Veterinárias, Jaboticabal, SP, Brasil. ${ }^{5}$ Universidade Estadual Paulista, Departamento de Apoio, Produção e Saúde Animal, Araçatuba, SP, Brasil. *Programa de Pós Graduação em Medicina Veterinária Preventiva. 
todas as categorias podem ser acometidas quando os surtos estão associados à ingestão de alimentos e água contaminados (BARros et al., 2006). Além disso, as características próprias do C. botulinum, ubiquitário do trato digestivo dos animais e do ambiente tornam a erradicação da doença algo impossível, fazendo com que a profilaxia seja a principal medida para o controle da enfermidade.

A vacinação dos animais de todo o rebanho, com toxoides bivalentes $\mathrm{C}$ e $\mathrm{D}$ de boa qualidade, aliada à correção da deficiência de fósforo e remoção das carcaças e/ou fontes de intoxicação das pastagens, são as principais medidas adotadas para se diminuir o risco da intoxicação (KRIEK; OdENDAAL, 1994). Em surtos naturais da doença, animais não vacinados de 6 a 24 meses de idade apresentam taxa de $96 \%$ de risco de intoxicação botulínica, e animais entre 2 e 6 meses $24 \%$, provavelmente protegidos por anticorpos maternos (SteinMAm et al., 2006).

Diante da importância da profilaxia na prevenção da doença, o presente estudo verificou pelo teste de ELISA indireto a resposta humoral contra as toxinas botulínicas tipos C e D em bovinos vacinados em diferentes faixas etárias. Sem histórico de vacinação prévia, 90 bovinos de ambos os sexos, da raça Nelore, pertencentes à Unidade de Pesquisa da Faculdade de Engenharia, Universidade Estadual Paulista, Campus de Ilha Solteira, onde surtos de botulismo já haviam ocorrido em anos anteriores, foram vacinados com uma vacina bivalente $C$ e D comercial, utilizando-se a via subcutânea e a dose recomendada pelo fabricante (5 mL). Os animais foram agrupados de acordo com a faixa etária, formando três grupos $(\mathrm{n}=30)$; animais com idade inferior a 2 anos (G1), entre 2 e 5 anos (G2) e superior a 5 anos (G3). A revacinação (booster) foi efetuada 42 dias após o estímulo primário (FONSECA, 2001) e as colheitas de sangue foram realizadas nos dias zero (início do experimento) e 30 após o booster.

As toxinas botulínicas (C e D) foram obtidas de culturas de cepas de C. botulinum, provenientes do Laboratório de Pesquisas em Enfermidades Infecciosas dos Animais, Universidade Estadual Paulista, Campus Araçatuba. Após o cultivo convencional em meio de cultura Cooked Meat Médium (CMM), o antígeno foi concentrado e semipurificado como de- scrito por QueIROZ (2001) e a concentração de proteína total, $6,7 \mathrm{mg} / \mathrm{mL}$ para a toxina $\mathrm{C}$ e $4,4 \mathrm{mg} / \mathrm{mL}$ para a toxina D, foi determinada pelo kit comercial BCA de proteína $\left(\right.$ Pierce ${ }^{\circledR}$. As amostras de soro sanguíneo dos bovinos foram submetidas individualmentee em duplicata à detecção de anticorpos contra as toxinas botulínicas tipos $\mathrm{Ce} \mathrm{D}$, pelo teste de ELISA indireto, seguindo as orientações de GREGORY (1996) com algumas modificações. As placas foram sensibilizadas com o antígeno diluídoem tampãocarbonato/bicarbonato (TCB), pH 9,6, e para a diluição do soro e conjugado utilizou-se "phosphate-buffered saline" (PBS), pH 7,4 . Soros na concentração de $5 \mathrm{UI} / \mathrm{mL}$ para o tipo C e $5 \mathrm{UI} / \mathrm{mL}$ para o tipo D (LANAGRO/MG) foram utilizados nos testes como controle positivo, e soros de bezerros recém-nascidos privados de colostro como controle negativo. As imunoglobulinas foram detectadas utilizando-se Anti-IgG bovina, conjugada com peroxidasena diluição de 1:5000 ea reação desenvolvida com substrato orto-fenileno-diamina (OPD).

As médias dos grupos (faixas etárias) foram comparadas pelo teste de Tukey e as estatísticas foram consideradas significativas quando $p<0,05$. As análises foram efetuadas empregando-se o programa SAS (Statistical Analysis System, 2001).

Os grupos de animais vacinados (G1, G2 e G3) com o produto comercial bivalente produziram resposta significativa de anticorpos contra as toxinas C e D (Tabela 1) quando avaliados 30 dias após o reforço vacinal. Algumas diferenças estatisticamente significativas foram observadas quando comparados os diferentes grupos experimentais separados de acordo com a faixa etária. Aos 30 dias pós-reforço vacinal, o G3, com idade acima de cinco anos, apresentou maior produção de anticorpos $(p<0,05)$ contra as toxinas tipos C e D, quando comparados aos demais grupos (Fig. 1). Entre os outros dois grupos de animais vacinados, não houve diferenças significativas na resposta contra a toxina $C$, enquanto para o tipo D, os animais do G1 apresentaram maior produção de anticorpos em relação ao G2. Além disso, foi possível observar no presente estudo que todos os grupos apresentaram uma magnitude na resposta humoral contra a toxina tipo $\mathrm{D}$ em relação à apresentada para o tipo C.

Tabela 1 - Média $(\overline{\mathrm{X}})$ e erro padrão da média (EPM) em mmHg, da densidade óptica inicial (DO - I) e 30 dias após a revacinação (DO - F), segundo a faixa etária e o tipo de toxina.

\begin{tabular}{|c|c|c|c|c|}
\hline \multirow{3}{*}{ Faixa etária (anos) } & \multicolumn{4}{|c|}{ Densidade óptica ( $\left.\overline{\mathrm{X}}_{ \pm \mathrm{EPM}}\right)$} \\
\hline & \multicolumn{2}{|c|}{ Anti C } & \multicolumn{2}{|c|}{ Anti D } \\
\hline & DO - I & $\mathrm{DO}-\mathrm{F}$ & DO - I & $\mathrm{DO}-\mathrm{F}$ \\
\hline Até 2 & $0,010 \pm 0,006$ & $0,273 \pm 0,014 \mathrm{bB}$ & $0,079 \pm 0,011$ & $0,505 \pm 0,052 \mathrm{bA}$ \\
\hline De 2 a 5 & $0,001 \pm 0,000$ & $0,297 \pm 0,023 \mathrm{bB}$ & $0,010 \pm 0,004$ & $0,412 \pm 0,035 \mathrm{bA}$ \\
\hline Acima de 5 & $0,031 \pm 0,008$ & $0,396 \pm 0,023 \mathrm{aB}$ & $0,120 \pm 0,020$ & $0,640 \pm 0,050 \mathrm{aA}$ \\
\hline
\end{tabular}




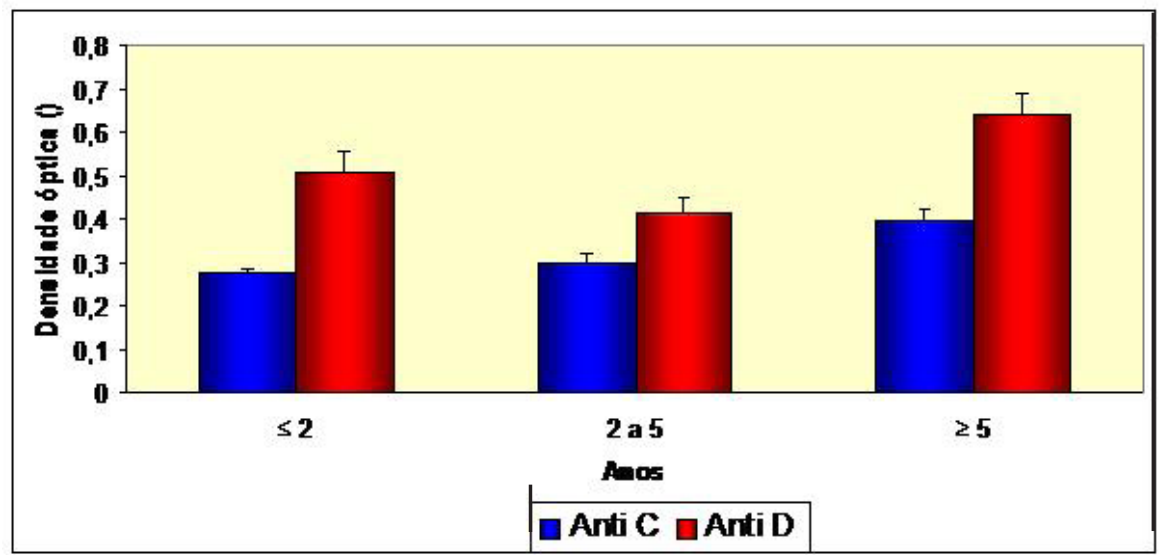

Fig. 1 - Resposta humoral de bovinos vacinados com toxóides botulínicos bivalentes C e D.

Os animais vacinados receberam a dose reforço aos 42 dias da dose primária. Este intervalo de revacinação foi determinado seguindo o protocolo de FONSECA (2001), que verificou o aumento na produção de anticorpos contra a toxina do tipo D, quando comparado ao protocolo comumente utilizado de 30 dias. $\mathrm{O}$ uso de vacinas antibotulínicas de boa qualidade tem sido recomendado, demonstrando em situação de alto risco a diminuição da probabilidade de animais vacinados serem acometidos pelo botulismo (DUTRA; DÖBEREINER, 1996). A enfermidade pode ocasionar perdas consideráveis no rebanho, uma vez que o tratamento na maioria das vezes é tardio e impraticável. A recomendação da utilização de vacinas contra o botulismo sempre esteve condicionada a ocorrência da enfermidadena propriedade ou região e em animais adultos. No entanto, com a alta contaminação ambiental pelo micro-organismo, associado ao aumento de surtos esporádicos da enfermidade por alimento e água contaminada, a vacinação tem sido uma grande aliada na prevenção da doença em todos os sistemas de produção e diferentes faixas etárias.

Pelo teste de ELISA indireto, nas condições em que foi realizado o presente estudo, o grupo de animais adultos, acima de cinco anos (G3), apresentou maior produção de anticorpos, fato este que pode ser causado por algum contato/desafio natural, uma vez que a propriedade da universidade possui histórico da enfermidade. Foi possível observar que todos os grupos apresentaram um aumento na produção de anticorpos contra as toxinas $\mathrm{Ce} \mathrm{D}$ após a revacinação dos animais, principalmente contra a toxina tipo D. Estes dados também foram observados em estudos de avaliação de vacinas antibotulínicas comercializadas no Brasil (Lobato et al., 1999; FonseCA, 2001; CURCI, 2008). Variações imunogênicas segundo o toxoide empregado na produção das vacinas ou ainda uma diferença na concentração antigênica final podem estar envolvidas.
Este trabalho foi aprovado pela Comissão de Ética na Experimentação Animal - CEEA - FOA/ UNESP, protocolo $n^{\circ}$ 006929-2008.

\section{AGRADECIMENTO}

Ao Fiscal Agropecuário Maurício B. de Carvalho Filho e Laboratório Nacional Agropecuário (LANA$\mathrm{GRO} / \mathrm{MG})$, pelas antitoxinas botulínicas.

\section{REFERÊNCIAS}

BARROS, C.S.L.; DRIEMEIER, D.; DUTRA, I.S.; LEMOS, R.A.A. Botulismo. In: (Ed.). Doenças do sistema nervoso de bovinos no Brasil. São Paulo: Vallée, 2006. Cap.10, p.57-62.

CURCI, V.C.M. Resposta humoral de bovinos para os toxóides botulinicos C e D. 2008. 36f. Tese (Doutorado em Medicina Veterinária Preventiva) - Faculdade de Ciências Agrárias e Veterinária) - Universidade Estadual Paulista, Jaboticabal, SP, 2008.

DUTRA, I.S. Epidemiologia, quadro clínico e diagnóstico pela soroneutralização em camundongo do botulismo em bovinos no Brasil, 1989-2001. 2001. 133f. Tese (Livre Docência) - Curso de Medicina Veterinária, Universidade Estadual Paulista, Araçatuba, SP, 2001.

DUTRA, I.S.; DÖBEREINER, J. Fatos e teorias sobre a "doença da vaca caída": botulismo. A Hora Veterinária, v.84, p.7-10, 1995.

DUTRA, I.S.; DOBEREINER, J. Eficácia da Vaxall - vacina botulínica bivalente - na prevenção do botulismo em bovinos. A Hora Veterinária, v.93, p.22-26, 1996.

DUTRA, I.S.; DOBERAINER, J.; ROSA, I.V.; SOUZA, L.A.A.; NONATO, M. Surtos de botulismo em bovinos 
no Brasil associados à ingestão de água contaminada. Pesquisa Veterinária Brasileira, v.21, n.2, p.43-48, 2001.

FONSECA, F.S. Comparação da resposta humoral de bovinos e cobaios vacinados com toxóides botulínicos bivalentes $C$ e D. 2001. 55f. Dissertação (Mestrado em Medicina Veterinária Preventiva) - Faculdade de Ciências Agrárias e Veterinárias, Universidade Estadual Paulista, Jaboticabal, SP, 2001.

GREGORY, A.R. Use of enzyme-linked immunoassays for antibody to types $C$ and $D$ botulinum toxins for investigations of botulism in cattle. Australian Veterinary Journal, v.73, n.2, p.55-61, 1996.

KRIEK, N.P.J.; ODENDAAL, M.W. Botulism. In: COETZER J.A.W.;THOMSON, G.R.; TUSTIN, R.C. (Ed.). Infectious diseases of livestock with special reference to Southern Africa. 2.ed. Cape Town: Oxford University Press, 1994. 1605p.

LOBATO, F.C.F.; ALMEIDA, A.C.; ABREU, V.L.V., SILVA, N.; NASCIMENTO, R.A.; MARTINS, N.E. Anticorpos neutralizantes em bovinos vacinados com toxóides botulínicos monovalentes e bivalentes tipos C e D. Revista Brasileira de Medicina Veterinária, v.21, n.1, p.25-27, 1999.

QUEIROZ, R.A. Desenvolvimento de teste de imunoadsorção enzimática para detecção de anticorpos contra as toxinas C e D de Clostridium botulinum em bovinos. 2001. 51f.

Dissertação (Mestrado Interinstitucional em Biologia
Parasitária) - Universidade Federal do Mato Grosso do Sul, Campo Grande, MS, 2001.

RIBAS, A.I.; FERREIRA, R.M.M; MASSER, R.C.; CIANI, R.B.; DUTRA, I.S. Detecção de esporos de Clostridium botulinum em costelas de cadáveres decompostos de bovinos. In: CONGRESSO BRASILEIRO DE MEDICINA VETERINÁRIA, 23., 1994, Olinda, PE. Anais. Olinda: Sociedade Brasileira de Medicina Veterinária, 1994. p.142.

SAS INSTITUTE. SAS On-lineDoc..Version 8. Cary, NC, 2001.

SOUZA, A.M.; MARQUES, D.F.; DOBEREINER, J.; DUTRA, I.S. Esporos e toxinas de Clostridium botulinum dos tipos C e D em cacimbas no Vale do Araguaia, Goiás. Pesquisa Veterinária Brasileira, v.26, n.3, p.133-138, 2006.

STEINMAN, A.; CHAFFER M.; ELAD, D.; SHPIGEL, N. Quantitative analysis of levels of serum immunoglobulin $G$ against Botulinum neurotoxin type D and association with protection in natural outbreaks of cattle botulism. Clinical and Vaccine Immunology, v.13, n.8, p.862-868, 2006.

TOKARNIA, C.H.; LANGENEGGER, J.; LANGENEGGER, C.H.; CARVALHO, E.V. Botulismo em bovinos no Estado do Piauí, Brasil. Pesquisa Agropecuária Brasileira, v.5, p.465-472, 1970.

Recebido em 29/9/11

Aceito em 14/2/13 